\title{
Iridium complex, a phosphorescent light-emitting diode material, serves as a novel chemical probe for imaging hypoxic tumor tissues
}

\author{
Shaojuan Zhang ${ }^{1 *}$, Masahiro Hosaka ${ }^{1,}$, Toshitada Yoshihara ${ }^{3 *}$, Yasuhiko Iida ${ }^{2}$, Keigo \\ Endo $^{2}$, Seiji Tobita ${ }^{3}$, and Toshiyuki Takeuchi ${ }^{1}$ \\ * The first three authors contributed equally to this work. \\ ${ }^{1}$ Secretion Biology Lab, Institute for Molecular and Cellular Regulation, \\ Gunma University, Maebashi 371-8512: ${ }^{2}$ Division of Diagnostic Radiology and Nuclear \\ Medicine, Graduate School of Medical Sciences, Gunma University, Maebashi 371-8511: \\ ${ }^{3}$ Department of Chemistry and Chemical Biology, Graduate School of Engineering, Gunma \\ University, Kiryu 376-8515, Japan
}

Running title: Iridium complex for cancer imaging

Key words: organic light-emitting diode, iridium complex, phosphorescence, oxygen quenching, hypoxia, cancer

Address correspondence:

Toshiyuki Takeuchi Secretion Biology Lab, Institute for Molecular and Cellular Regulation, Gunma University, Showa-machi, Maebashi 371-8512, Japan

TEL +81-272-20 8855

FAX +81-272-20-8896

E mail tstake@showa.gunma-u.ac.jp 
Iridium complex, a promising organic light-emitting diode for next generation televisiom display, emits phosphorescence. Phosphorescence is quenched by oxygen. We used this oxygen-quenching feature for imaging tumor hypoxia. Red light-emitting iridium complex $\operatorname{Ir}(\text { btp) })_{2}$ (acac) (BTP) presented hypoxia-dependent light emission in culture cell lines, whose intensity was in parallel with HIF-1 $\alpha$ expression. BTP was further applied to imaging five tumors (four from human origin and one from mouse origin) transplanted in athymic mice. All tumors presented a bright BTP-emitting image even 5 min after the injection. The BTP-dependent tumor image peaked at 1 to $2 \mathrm{~h}$ after the injection, and was then cleared off from tumors within $24 \mathrm{~h}$. The minimal BTP image recognition size was 3 to $4 \mathrm{~mm}$ in diameter. Compared with ${ }^{18}$ F-FDG/PET images, BTP delineated a clearer image for a tumor profile. We suggest that iridium complex has a vast potential for imaging hypoxic lesions such as tumor tissues. (150 words) 
An organic light-emitting diode (OLED) is a promising device for thinner, lighter, and higher-resolution displays for next generation televisions, computers, electronic books, and billboards $(1,2)$. As a low voltage-powered OLED emitter, Tang and VanSlyke introduced tris(8-hydroxyquinolinato)aluminum ( $\mathrm{Alq}_{3}$ ) to an organic thin film device (3). In 1990 Friend and colleagues incorporated another device, a conducting polymer poly(p-phenylenevinylene), as an OLED emitter. Since then, enormous progress has been made towards the advancement of OLED emitter technology $(1,2)$. These $\mathrm{Alq}_{3}$ and their derivative devices and conducting polymers emit fluorescence, whose electroluminescence efficiency (quantum yield) is limited to $25 \%$ at maximum. In contrast to fluorescent OLED devices, a new type of organometallic phosphorescent OLEDs was introduced around the turn to the new century (4). Such a highly attractive OLED is exemplified by iridium complex, $\operatorname{Ir}(\mathrm{btp})_{2}(\mathrm{acac}) \quad$ (BTP; bis(2-(2'-benzothienyl)-pyridinato-N,C ${ }^{3}$ )iridium(acetylacetonate) (5). Phosphorescence is superior to fluorescence in terms of its internal quantum yield. Fluorescence emits light from singlet states whose spin statistics are predicted at a maximum $25 \%$ of charge recombinations while spin statistics of phosphorescence start from triplet states, thus the upper limit of the internal quantum yield increases from 25\% to nearly $100 \%$ (2). Furthermore, phosphorescence exhibits another conspicuous feature, oxygen quenching, by which iridium complex devices have to be shielded from the exposure to oxygen. This property suggests that the iridium complex devices emit phosphorescence, depending inversely on oxygen concentrations.

Hypoxia is highly notable in tumor tissues $(6,7)$, where hypoxia-inducible factor (HIF)-1 $\alpha$ is induced by inhibiting its degradation through the decrease in oxygen-sensing prolyl 4-hydroxylase activity (8,9). HIF-1 $\alpha$ regulates a variety of gene expressions including vascular endothelial growth factor (VEGF), erythropoietin, and glucose transporter (Glut)-1. Through HIF-1 $\alpha$-mediated gene expression, tumors are vascularized by VEGF to receive oxygen and nutrients for their growth in a hypoxic milieu (7). Several hypoxia-associated probes have been developed for tumor imaging including nitroimidazole $(10,11)$, Cu-diacetyl-bis( $N^{4}$-methylthiosemicarbazone (Cu-ATSM) (12), and fluorodeoxyglucose (FDG) (13). Nitroimidazole and Cu-ATSM are thought to bind to macromolecules in a 
hypoxia-induced redox state-dependent manner. FDG is extensively taken up into tumor cells through glucose transporter 1 (Glut1), which is up-regulated by HIF-1 $\alpha(7,13)$. They are used with radioisotope labeling for visualization by positron emission tomography (PET).

An optical method was demonstrated to directly detect oxygen in cells and tissues by using oxygen-dependent quenching of phosphorescence to visualize oxygen distribution in vivo (14). For this purpose, several kinds of phosphorescent probes such as metalloporphyrins and ruthenium(II) complexes have been developed $(15,16)$. Since the phosphorescence of these organic compounds was extremely weak owing to their spin-forbidden nature even under a deaerated condition, heavy metal was placed in the center to induce the active mixing effect of the spin state on the $\pi$-electronic system of the ligands for enhancement of phosphorescence intensity. Phosphorescent oxygen probes have been developed by decorating "molecular coats” to oxygen-sensitive heavy metal complexes $(15,17.18)$. The molecular coats protect the phosphor from the environment and give them hydrophilic nature, but their molecular size enlarges to over 2000 Da exemplified by the paradium-porphyrin complex (15). These phosphorescent probes have been applied to measure oxygen pressure in microcapillary vessels because these probes cannot penetrate into the plasma membrane due to their size and hydrophilic nature $(15,17,19)$.

Compared with the first stage phosphorescence probes, iridium complexes possess highly phosphorescent and photostable properties which are required for use of OLED emitters. Furthermore, we are able to employ various kinds of ligands to improve the photophysical and chemical properties (absorption and emission wavelengths, solubility, toxicity, etc.) for achieving optimal properties suitable to image hypoxic tissues. In this study, we employed the well-known red-emitting iridium complex $\operatorname{Ir}(\mathrm{btp})_{2}(\mathrm{acac})(\mathrm{BTP})$ (Fig. 1a) as a phosphorescent probe. The red phosphorescence of BTP is advantageous for tissue penetrance, and its moderately long lifetime (5.8 $\mu$ s in deaerated 1,2-dichloroethane) is favorable for oxygen-induced quenching. Based on these reasons, we applied this phosphorescent probe for hypoxic tumor imaging to test its feasibility. 


\section{RESULTS}

\section{Photophysical properties of BTP complexes}

Since the chemical structure of BTP appears lipophilic (Fig. 1a), we examined its uptake into an artificial membrane composed of dimyristoyl-L- $\alpha$-phosphatidylcholine (DMPC, $1 \mathrm{mM}$ ). Indeed, over 98\% of BTP was partitioned into the membrane when BTP (10 $\mu \mathrm{M})$ was dissolved in Tris- $\mathrm{HCl}$ buffer at $35^{\circ} \mathrm{C}$. We then investigated the photophysical properties of BTP in DMPC liposome as well as in 1,2-dichloroethane and $n$-hexane solutions. BTP in a deaerated 1,2-dichloroethane solution showed the first absorption maximum at $483 \mathrm{~nm}$ with a molar absorption coefficient of $6,100 \mathrm{M}^{-1} \mathrm{~cm}^{-1}$, and showed intense phosphorescence from a ligand-centered $\pi \pi^{*}$ state (promotion of a $\pi$-electron to an antibonding $\pi^{*}$ orbital) with significant admixtures of metal-to-ligand charge transfer (electron promotions from metal-centered to ligand-centered orbitals) character at $616 \mathrm{~nm}$ (Fig. 1b). The phosphorescence quantum yield $\left(\Phi_{\mathrm{p}}^{0}\right)$ and lifetime $\left(\tau_{\mathrm{p}}{ }^{0}\right)$ in a deaerated 1,2-dichloroethane solution ( $\mathrm{pO}_{2}$ is assumed to be 0 ) were 0.32 and $5.8 \mu$ s, respectively, at room temperature. The phosphorescence quenching due to dissolved oxygen in solution or membrane can be obtained by the following Stern-Volmer equation:

$$
\frac{\Phi_{\mathrm{p}}^{0}}{\Phi_{\mathrm{p}}}=\frac{\tau_{\mathrm{p}}^{0}}{\tau_{\mathrm{p}}}=1+k_{\mathrm{q}} \tau_{\mathrm{p}}^{0} p \mathrm{O}_{2},
$$

where $\Phi_{\mathrm{p}}$ and $\tau_{\mathrm{p}}$, respectively, are the phosphorescence quantum yield and phosphorescence lifetime at an oxygen partial pressure $\mathrm{pO}_{2}$, and $k_{\mathrm{q}}$ is a bimolecular quenching rate constant (20). At $35^{\circ} \mathrm{C}$, the $k_{\mathrm{q}}$ value in $n$-hexane was determined to be $5.7 \times 10^{4} \mathrm{mmHg}^{-1} \mathrm{~s}^{-1}$ (mmHg=millimeters of mercury) and that in DMPC membrane in Tris-HCl buffer $(\mathrm{pH}=7.0)$ was $1.2 \times 10^{4} \mathrm{mmHg}^{-1} \mathrm{~s}^{-1}$. When $\tau_{\mathrm{p}}{ }^{0}=5.3 \mu \mathrm{s}\left(\tau_{\mathrm{p}}^{0}\right.$ in DMPC membrane) and tissue $\mathrm{pO}_{2}=60$ mmHg are applied to this equation and assuming that the quenching rate constants in the membrane and tissue are equal, $\Phi_{\mathrm{p}}^{0} / \Phi_{\mathrm{p}}$ comes to 4.8, indicating that BTP phosphorescence will be quenched in the tissue $\mathrm{pO}_{2}$ milieu of $60 \mathrm{mmHg}$. Since $\mathrm{pO}_{2}=60 \mathrm{mmHg}$ is not hypoxic as a tissue $\mathrm{pO}_{2}$ (7), BTP is presumed to become phosphorescent at lower $\mathrm{pO}_{2}$ than $60 \mathrm{mmHg}$, so it appears to be applicable to hypoxic tissue $\mathrm{pO}_{2}$ estimation. 


\section{Iridium complex BTP to culture cells in a hypoxic milieu}

Since the oxygen quenching feature of BTP appeared to be regulated in a physiological tissue $p \mathrm{O}_{2}$ milieu by the photophysical evaluation, we examined the oxygen quenching using culture cell lines. Three cell lines, human uterine cancer-derived HeLa, Chinese hamster ovary-derived $\mathrm{CHO}$, and human glioma-derived $\mathrm{U} 251$, were placed in a $5 \% \mathrm{O}_{2}$ culture condition. In normoxia, the three cell lines did not exhibit notable phosphorescence when loaded with BTP $(50 \mu \mathrm{M})$ (Fig. 2a). In contrast, the three cell lines emitted bright red phosphorescence in a 5\% $\mathrm{O}_{2}$ culture (Fig. 2a). We then observed the phosphorescence of BTP in decreasing $\mathrm{O}_{2}$ levels from 20\% to 2.5\% using HeLa cells (Fig. 2b, upper panel). With a decrease in $\mathrm{O}_{2}$ concentration, the phosphorescence increased in an inverted manner. Likewise, HIF-1 $\alpha$ was increasingly immunostained with a decrease in $\mathrm{O}_{2}$ levels (Fig. 2b, lower panel). In accordance with this, HIF-1 $\alpha$ protein gradually displayed an intensive band with the increasing intensity of phosphorescence (Fig. 2c). Since we observed the BTP phosphorescence emission in a hypoxia-dependent manner, we tested this probe to image tumors transplanted in athymic nude mice.

\section{BTP to tumor-bearing nude mice}

We used five culture cell lines for transplantation; human oral squamous carcinoma-derived SCC-7, human glioma-derived U87, human lymphoma-derived RAMOS, human colon carcinoma-derived HT-29, and mouse lung cancer-derived LL-2. Tumor size varied from 10 to $15 \mathrm{~mm}$. The histopathological features of each tumor were examined as follows: SCC-7, poorly differentiated carcinoma without any keratinization; U87, spindle-shaped glial cells with marked atypia; RAMOS, medullary growth of large atypical lymphocytes; HT-29, poorly differentiated adenocarcinoma cells forming tubular structures; and LL-2, poorly differentiated adenocarcinoma cells with intracytoplasmic vacuoles (Supplementary Fig. 1). Tumors grown from culture cells tended to show undifferentiated features. We then measured $\mathrm{pO}_{2}$ by an oxygen monitoring probe, and found that median $\mathrm{pO}_{2}$ ranged from 18 to $21 \mathrm{mmHg}$ (Table 1). Thus, the $\mathrm{pO}_{2}$ of each tumor was lower than that of end-capillary blood whose $\mathrm{pO}_{2}$ ranges 
from 45 to $50 \mathrm{mmHg}$ (7). However, since Höckel and Vaupel stated that the critical $\mathrm{pO}_{2}$ below 8-10 mmHg is associated with detrimental hypoxic changes such as decrease in cellular ATP levels (8), the $\mathrm{pO}_{2}$ levels in the five tumors appear to come under the moderate hypoxia criteria. To examine the expression of HIF- $1 \alpha$, we immunostained HIF- $1 \alpha$ in the five tumors. HIF-1 $\alpha$ was well stained in SCC-7 and HT-29 tumors, but was not well notable in the other tumors (Supplementary Fig. 1).

We dissolved BTP in dimethylsulfoxide (DMSO) because it was lipophilic. The BTP dose was determined using SCC-7 tumor-bearing mice by injecting $25 \mathrm{nmol}, 125 \mathrm{nmol}, 250$ nmol, and $500 \mathrm{nmol} /$ mouse, and 250 and $500 \mathrm{nmol} \mathrm{BTP/mouse} \mathrm{was} \mathrm{found} \mathrm{to} \mathrm{clearly} \mathrm{depict} \mathrm{a}$ tumor image (Supplementary Fig. 2). BTP (250 nmol/100 $\mu \mathrm{l}$ DMSO) was injected from the tail vein under pentobarbital anesthesia. Each tumor-bearing mouse was placed in a dark box of the Maestro In-Vivo imaging System. Luminescence was detected 5 min after the injection in all five tumors, and it increased gradually to a 1 h-point (Fig. 3a). The shape and position of the luminescence spectra emitted from the tumors were identical with those of the phosphorescence spectrum of BTP shown in Fig. 1b, suggesting that BTP chemical structure was maintained in a spectrum basis (data not shown). Extra-tumor regions are generally non-luminescent, but when anesthesia is overdosed, the forearm, peri-oral and peri-nasal regions began to turn red.

We then determined the fate of BTP using SCC-7 tumors in athymic nude mice. The intensity of BTP was highest at $2 \mathrm{~h}$ after the injection, then declined gradually towards the 24-h point, when the tumor was not imaged (Fig. 3b). We measured the $\mathrm{pO}_{2}$ level before and periodically after the BTP administration, and found that $\mathrm{pO}_{2}$ levels are not affected by BTP administration even after the peak of BTP phosphorescence (data not shown).

\section{Detection limit of tumor size and imaging depth}

We examined the detection limit of BTP-imaged tumor size. SCC-7 cells were injected into athymic nude mice and their tumor size was monitored daily. When the tumor reached $2 \mathrm{~mm}$ and more in diameter, we began to assess BTP imaging. When a tumor grew to $4 \mathrm{~mm}$ in diameter, its BTP-imaging was reliably detected (Fig. 4). 
One of the drawbacks of luminescent imaging is the penetration limit of luminescence. Although a red to near-infrared wavelength $(>630 \mathrm{~nm})$ is preferable for tissue penetration both in excitation and emission, the excitation wavelength of BTP is $483 \mathrm{~nm}$ at maximum although its emission is $616 \mathrm{~nm}$ at its first peak and $680 \mathrm{~nm}$ at its second peak (Fig. 1b). We measured the detection limit of BTP-imaging by placing a $1.2 \mathrm{~mm}$ slice of beef meat on a BTP gel composed of polyacrylamide. We could detect the BTP-imaging at a depth of $4.8 \mathrm{~mm}$ by 20 nmol BTP and $7.2 \mathrm{~mm}$ by $200 \mathrm{nmol} \mathrm{BTP}$, but it was more difficult to detect a depth of $8.4 \mathrm{~mm}$ from the surface (Supplementary Fig. 3). Thus, to obtain much deeper tissue penetration, BTP should be modified for excitation by a red to near-infrared wavelength.

\section{Comparison of BTP-imaging with ${ }^{18}$ F-FDG-imaging}

The BTP image depicted tumor profiles almost accurately in each tumor. Since FDG-PET is routinely used for screening dormant tumors in medicine, we compared the BTP-imaging with FDG-PET imaging. We selected similar size tumors grown on the right pelvic region, one for BTP-imaging and the other for ${ }^{18}$ F-FDG-imaging. The BTP image was limited to tumor profiles in each tumor, whereas the ${ }^{18}$ F-FDG-image looked vague in all five mice. We could barely find a limited image in the U87MG, and HT-29 tumors (Supplementary Fig. 4). Apart from tumor-imaging, the ${ }^{18}$ F-FDG-image was distributed to non-tumor tissues such as the brain and the heart, and resulted in widely spreading images in each mouse. Thus, we suggest that BTP-image is much clearer than ${ }^{18}$ F-FDG-image.

\section{Toxicity}

As the first step for evaluating BTP toxicity, we examined cell viability using HeLa cells by trypan blue dye-exclusion assay and apoptosis by staining with Hoechst 33342 DNA binding dyes plus propidium iodide fluorescence. We used cholesterol as a negative control and 7-ketocholesterol as a positive control because both are lipophilic similar to BTP (21). Both cell viability and apoptosis by BTP were similar to those in the cholesterol control (Supplementary Fig. 5). 


\section{DISCUSSION}

We demonstrated a promising potential of phosphorescent OLED, iridium complex, for tumor imaging. To visualize hypoxic tissues, phosphorescence is superior to fluorescence because of one of its specific features, oxygen quenching. Using this feature, phosphorescent probes such as BTP can be visualized in a hypoxic milieu such as tumors. Tumors were visible even 5 min after the BTP injection (Figs. 3a). The luminescent region became widespread over the tumor profile 1 to $2 \mathrm{~h}$ after the BTP injection, and disappeared within $24 \mathrm{~h}$ (Fig. 3b). In a tumor-bearing mouse, BTP is distributed systemically to its whole body, and emits phosphorescence where oxygen supply is insufficient. In this sense, iridium complex is distinct in its luminescence emission in comparison to other tumor-detecting probes, such as nitroimidazole, $\mathrm{Cu}(\mathrm{II})-\mathrm{ATSM}$, and ${ }^{18} \mathrm{~F}$-FDG. In other words, iridium complex is a hypoxia-sensing emitter, while the above three are a hypoxia-accumulating emitter. For example, nitroimidazole accumulates in a hypoxic tissue where the nitro residues are reduced by the lack of sufficient oxygen, and a reduced form of nitroimidazole is thought to bind to macromolecules (11,22). Nitroimidazole has been developed for use with a radioisotope-labeled PET probe, such as $\left[{ }^{18} \mathrm{~F}\right]$-fluoromisonidazole (FMISO) (23) and $\left[{ }^{18} \mathrm{~F}\right]$-fluoroetanidazole (24). $\mathrm{Cu}(\mathrm{II})$-ATSM is also reduced in hypoxic tissue to release $\mathrm{Cu}(\mathrm{I})$, which is thought to bind to macromolecules. Thus, when $\mathrm{Cu}$ is radiolabeled as ${ }^{60} \mathrm{Cu},{ }^{61} \mathrm{Cu}$, ${ }^{62} \mathrm{Cu}$, or ${ }^{64} \mathrm{Cu}$, radiolabeled $\mathrm{Cu}$ is trapped in the hypoxic tissue (25). These probes should be radiolabeled for PET and requires cost-taking PET facilities and equipments.

Recently, quantum dots (QDs) have attracted much attention as a fluorescent probe for tumor imaging, although tumor imaging mechanisms of QDs do not depend on hypoxia $(26,27)$. But tumor vasculature has large penetration gaps for macromolecules such as nanometer-size QD particles. Furthermore, QD has been extensively modified by decorating a variety of molecules for better trapping to tumor tissues $(28,29)$. QDs are made of CdSe-ZnS in their core shell (27). Thus, QDs are used for shielding with a safe lining because Cd is toxic (30). Although QDs may be safe in the body, excreted QDs from animals, and animals retained with QDs have to be disposed safely. Thus, the toxicity problem of QDs has not been settled yet $(30,31)$. On the other hand, iridium complex appears to be safe based on a 
preliminary toxicity experiment (Supplementary Fig. 5). We also noted that mice were healthy for over three months after a high dose injection of BTP (data not shown).

${ }^{18}$ F-FDG is most frequently used for PET as a probe for tumor imaging (32). FDG is taken up to cells through Glut1, and its retention to tumors depends on the balance between hexokinase and glucose-6-phosphatase (G6Pase) activities (13). In a hypoxic condition, Glut1 is induced by HIF-1 $\alpha$ for increasing uptake of glucose (8-10). FDG is phosphorylated to FDG-6-P by hexokinase, but FDG-6-P cannot be converted further to fluorodeoxyfructose 6-phosphate by phosphohexose isomerase because hydroxyl residue at position 2 is replaced by fluorine. Conversely, FDG-6-P can be reversed to FDG by G6Pase if G6Pase activity is high, and as a result, FDG may be removed out from the cell. Since tumors such as early prostate cancer and well-differentiated hepatoma have high G6Pase activity, FDG/PET is not adequate for the detection of these tumors (13). In this study, FDG/PET did not depict a clear tumor image in all five tumors compared with BTP-imaged tumors (Supplementary Fig. 4). FDG/PET resulted in bright images in non-tumor-residing regions, perhaps reflecting an FDG-incorporating brain, heart, and muscle images in all mice. Further, FDG/PET imaging barely delineates a tumor profile. Thus, the BTP image looks much better in depicting a tumor profile than FDG image.

But luminescent probes have an inevitable drawback, that is, their weak tissue penetration capacity, which is reportedly about $1 \mathrm{~cm}$ deep even when near-infrared wavelength light was used (26). The phosphorescence of BTP appears in the red to near-infrared region $(>615 \mathrm{~nm})$, while the excitation wavelength is limited to the visible light region (445-490nm). Indeed, when we placed a mouse with the tumor underneath, we could not detect the BTP-imaged tumor profile perhaps due to its approximately $3 \mathrm{~cm}$-thick body. To determine a depth-dependent detection limit, we placed a $1.2 \mathrm{~mm}$ slice of pork meat on a BTP polyacrylamide gel (20 nmole and 200 nmole of BTP/200 $\mu \mathrm{l}$ gel), and could detect phosphorescence approximately 5-7 mm deep from the surface depending on the BTP dosage (Supplementary Fig. 3). We further improved BTP by adding phenyl residues (BTQ) thus making the excitation wavelength shift $540 \mathrm{~nm}$ longer. But the penetration limit stayed in a similar range to that of BTP (data not shown). Thus, BTP imaging is preferable when tumors 
are situated close to the tissue surface. In this sense, we suggest that BTP imaging may be a promising technique for the detection of gastrointestinal tumors involving mucosal to submucosal layers with use of an endoscope. Since the detection limit of tumor size was estimated to be approximately $4 \mathrm{~mm}$ in diameter (Fig. 4), microadenoma and microcancer appear to be a target of BTP imaging. We suggest that iridium complex has practical feasibility for tumor hypoxia imaging, and it will have a promising potential for a hypoxia-indicating chemical probe in assistance with other imaging techniques such as PET scanning and endocytoscopy. 


\section{METHODS}

Physicochemical features of iridium complex. BTP was synthesized according to the previous literature (5). A mixture of 2-(benzo[b]thiophen-2-yl)pyridine (460 mg, $2.2 \mathrm{mmol}$ ), $\mathrm{IrCl}_{3} \cdot 3 \mathrm{H}_{2} \mathrm{O}$ (390 mg, $\left.1 \mathrm{mmol}\right)$, 2-ethoxyethanol $(30 \mathrm{ml})$, and distilled water $(10 \mathrm{ml})$ was heated at reflux for $15 \mathrm{~h}$. After cooling, the precipitate formed was filtered to give a chloro-bridged dimer and washed thoroughly with methanol and $n$-hexane. To the mixture of the chloro-bridged dimer (260 mg, $0.2 \mathrm{mmol}$ ) and $\mathrm{Na}_{2} \mathrm{CO}_{3}(170 \mathrm{mg}, 1.6 \mathrm{mmol}$ ), 2-methoxyethanol $(30 \mathrm{ml})$ and acetyl acetone $(1.0 \mathrm{ml}, 9.5 \mathrm{mmol})$ were added, and then the slurry was refluxed for $2 \mathrm{~h}$. After the mixture was cooled down, the precipitate formed was collected by filtration and washed thoroughly with methanol and $n$-hexane. Yield: $180 \mathrm{mg}$ (62 \%). ${ }^{1} \mathrm{H}$ NMR (300 MHz, $\mathrm{CDCl}_{3}$ ) $\delta: 8.43$ (d, 2H, J = 5.4 Hz), 7.77 (t, 2H, J = 8.4 Hz), 7.63 (d, 4H, J = 7.2 Hz), 7.07-6.99 (m, 4H), 6.80 (t, 2H, J = 7.8), 6.20 (d, 2H, J = 8.1 Hz), 5.26 (s, 1H), 1.78 (s, 6H).

Dimyristoyl-L- $\alpha$-phosphatidylcholine (DMPC; Sigma 99\%) was used for lipid membrane and liposome preparation. 1,2-Dichloroethane (DCE; Kishida, spectroscopic grade) was used without further purification. Deionized water was purified by using a Millipore (MILLI-Q-LABO). Small unilamellar vesicles were prepared by ethanol injection method. The ethanolic solution of DMPC $\left(3.0 \times 10^{-2} \mathrm{moldm}^{-3}, 0.1 \mathrm{ml}\right)$ was injected rapidly into Tris/HCl buffer $(2.85 \mathrm{ml}, \mathrm{pH}=7.0)$ at $50^{\circ} \mathrm{C}$. The incorporation of BTP to the small unilamellar liposome vesicles was carried out by adding a stock solution of BTP $\left(6.0 \times 10^{-4} \mathrm{moldm}^{-3}, 0.05\right.$ $\mathrm{ml}$ ) in DMSO. The final concentration of the BTP probe was $1.0 \times 10^{-5} \mathrm{moldm}^{-3}$. The solution was equilibrated for $1 \mathrm{~h}$ above the phase transition temperature $\left(23^{\circ} \mathrm{C}\right)$ of DMPC.

Absorption and emission spectra were measured with an UV/vis spectrophotometer (Jasco, Ubest-V550) and a spectrofluorimeter (Hitachi, F-4010), respectively. The emission spectrum was corrected for spectral sensitivity.

Cell culture and BTP uptake. We used three cell lines, human uterine cancer-derived HeLa, Chinese hamster ovary-derived $\mathrm{CHO}$, and human glioma-derived U251. We also used $\mathrm{O}_{2}$ concentration-changeable multi-gas incubator MCO-5M (Sanyo, Osaka, Japan). Cells were 
cultured in Dulbecco's modified Eagle's medium (DMEM, Invitrogen) containing $25 \mathrm{mmol} / \mathrm{l}$ glucose with $10 \%$ fetal bovine serum at $37^{\circ} \mathrm{C}$. The $\mathrm{O}_{2}$ concentration was changed from $20 \%$ to 10, 5.0, to $2.5 \%$. The cells were cultured under four $\mathrm{O}_{2}$ concentrations, $2.5 \%, 5 \%$, 10\%, or $20 \%$ for $24 \mathrm{~h}$ at $37^{\circ} \mathrm{C}$. Then, BTP was added to the medium at a final concentration of $50 \mu \mathrm{M}$ for $1 \mathrm{~h}$ for visualization (535 nm excitation/580 nm emission).

Tumor transplantation to nude mice. We conducted our animal experiments in accordance with the guidelines for the Care and Use of Laboratory Animals of the Medical Research Council of Gunma University. Tumor transplants were established in female athymic nude mice by injection of $1 \times 10^{7}$ human oral squamous carcioma-derived SCC-9, human glioma-derived U87, human lymphoma-derived RAMOS, human colon carcinoma-derived HT-29, and mouse lung cancer-derived LL-2. Experiments with tumor-bearing mice were performed two weeks after injection of tumor cells.

Immunostaining and immunoblot. Tumors were quickly removed, and fixed with $4 \%$ paraformaldehyde/0.1M phosphate buffer. Histological sections from cryostat blocks were stained with hematoxylin and eosin (HE). For HIF-1 $\alpha$ immunostaining, cryostat specimens or fixed cells were stained with a mouse monoclonal antibody to HIF-1 $\alpha$ (dilution 1:200, Sigma-Aldrich), then with a second immunostaining with the Labelled Streptavidin-Biotin2 System with horseradish peroxidase (LSAB2 System, Dako).

The expressions of HIF-1 $\alpha$ were measured by immunoblotting. HeLa cells were lysed in a lysis buffer [50 mM HEPES (pH 7.0), $250 \mathrm{mM} \mathrm{NaCl,} \mathrm{0.1 \%} \mathrm{Nonidet} \mathrm{P-40,} 100 \mathrm{mM} \mathrm{NaF}$, $0.2 \mathrm{mM}$ sodium orthovanadate, $0.5 \mathrm{mM}$ phenylmethylsulfonyl fluoride, $10 \mu \mathrm{g} / \mathrm{ml}$ aprotinin, 10 $\mu \mathrm{g} / \mathrm{ml}$ leupeptin, and $10 \mu \mathrm{g} / \mathrm{ml}$ pepstatin]. Cell lysates (15 $\mu \mathrm{g}$ protein/lane) were separated on a SDS-PAGE for nitrocellulose membrane blotting. The blotted membranes were incubated with the antibody to HIF-1 $\alpha$.

In vivo imaging. Luminiscence images of a whole mouse body and close-up image were obtained using the Maestro FL500 in vivo imaging system (CRi, Inc., Woburn, MA). A 
band-pass filter from 445 to $490 \mathrm{~nm}$ and a long-pass filter over $515 \mathrm{~nm}$ were used for excitation and emission light, respectively. The tunable filter was automatically stepped in 10-nm increments from 550 to $800 \mathrm{~nm}$ while the camera captured images at each wavelength interval with $1500 \mathrm{~ms}$ exposure. The spectral fluorescence images consisting of auto-fluorescence spectra and BTP spectra were obtained and then unmixed, based on their spectral patterns using commercial software (Maestro software, CRi, Inc.). The spectra for unmixed image are shown in Fig. 3 (Blue and sky-blue are auto-fluorescence; Red is BTP spectra). For BTQ imaging, a band-pass filter from 503 to $555 \mathrm{~nm}$ and a long-pass filter over $580 \mathrm{~nm}$ were used for excitation and emission light.

Measurement of oxygen partial pressure. Oxygen partial pressure $\left(\mathrm{pO}_{2}\right)$ in the tumors was measured with a needle-type polarographic oxygen electrode (PO2-150S, Eikou-kagaku Co. Ltd., Tokyo, Japan). The $\mathrm{pO}_{2}$ monitoring system has been commonly used in physiologic and anesthetic research, and details of this machine have been reported previously (33). An oxygen electrode probe of a $200 \mu \mathrm{m}$ diameter was inserted into tumors of immobilized mice without general anesthesia, and then $\mathrm{pO}_{2}$ was measured at least 10 different points in each tumor and the mean $\mathrm{pO}_{2}$ was calculated. After the measurement, the tumors were excised and weighed.

PET scanning for tumor-bearing mice. Whole-body small-animal PET imaging was performed on a micro-PET scanner (Inveon, Siemens Medical Solutions USA, Inc., Knoxville, TN). Imaging studies were carried out on BALB/c nude mice (7 weeks old, female) bearing subcutaneous SCC-9, U87MG, RAMOS, HT-29 and LL-2 tumors. The mice were injected via the tail vein with $10 \mathrm{MBq}$ of ${ }^{18} \mathrm{~F}$-FDG. These mice were fasted for at least $6 \mathrm{~h}$ prior to administration of ${ }^{18}$ F-FDG. Just before imaging, mice were anesthetized with pentobarbital, placed in the prone position and imaged. Each 10 minute static data sets were collected for 60 min. 


\section{ACKNOWLEDGEMENTS}

We would like to thank Dr. Chihaya Adachi (Kyushu University) for his helpful discussion, and Dr. Takashi Nakajima (Gunma University) for diagnosing histopathological features of athymic mouse-transplanted tumors. We also thank Ms. Mari Kosaki, and Ms. Mari Hosoi (Gunma University) for their secretarial and technical support. This work was supported by Grants-in-Aid for Basic Sciences and a grant of the Global COE program from the Ministry of Education, Culture, Sports, Science and Technology of Japan, and by a Grant-in-Aid (Collaborative Development of Innovative Seeds) from JST (Japan Science and Technology Agency).

\section{AUTHOR CONTRIBUTIONS}

S.Z. and M.H. cultured cell lines, imaged BTP in cells under hypoxia and in tumors transplanted in athymic mice, and conducted data analysis. T.Y. and S.T. synthesized BTP and measured its physicochemical features. Y.I. and K.E. supervised in vivo imaging of BTP and performed PET scanning of tumor-beaing mice. T.T. supervised the project.

\section{COMPETING INTERESTS STATEMENT}

The authors declare no competing financial interests. 


\section{REFERENCES}

1. Hung, L.S. \& Chen, C. Recent progress of molecular organic electroluminescent materials and devices. Materials Science and Engineering : R-Report 39, 143-222 (2002).

2. Evans, R.C., Douglas, P. \& Winscom, C.J. Coordination complexes exhibiting room-temperature phosphrescence: evaluation of their suitability as triplet emitters in organic light emitting diodes. Coordination Chemistry Reviews 250, 2093-2126 (2006).

3. Tang, C. W. \& VanSlyke, S. A. Organic electroluminescent diodes. Appl Phys Lett 51, 913-915 (1987).

4. Baldo, M.A., O’Brien, D.F., You, Y., Shoustikov, A., Sibley, S., Thompson, M.E. \& Forrest, S.R. Highly efficient phosphorescent emission from organic electroluminescent devices. Nature 395, 151-154 (1998).

5. Lamansky, S., Djurovich, P., Murphy, D., Abdel-Razzaq, F., Lee, H-E., Adachi, C., Burrows, P.E., Forrest, S.R. \& Thompson, M.E. Highly phosphorescent bis-cyclometalated iridium complexes: synthesis, photophysical characterization, and use in organic light emitting diodes. J Am Chem Soc 123, 4304-12 (2001).

6. Brahimi-Horn, C., Berra, E. \& Pouysségur, J. Hypoxia: the tumor's gateway to progression along the angiogenic pathway. Trends Cell Biol 11, S32-6 (2001).

7. Höckel, M. \& Vaupel, P. Tumor hypoxia: definitions and current clinical, biologic, and molecular aspects. J Natl Cancer Inst 93, 266-76 (2001).

8. Ryan, H.E., Poloni, M., McNulty, W., Elson, D., Gassman, M., Arbeit, J.M. \& Johnson, R.S. Hypoxia-inducible factor- $1 \alpha$ is a positive factor in solid tumor growth. Cancer Res 60, 4010-5 (2000).

9. Schofield, C.J. \& Ratcliffe, P.J. Oxygen sensing by HIF hydroxylases. Nat Rev Mol Cell Biol 5, 343-54 (2004).

10. Nunn, A., Linder, K. \& Strauss, H.W. Nitroimidazoles and imaging hypoxia. Eur J Nucl Med 22, 265-80 (1995).

11 Padhani, A.R., Krohn, K.A., Lewis, J.S. \& Alber, M. Imaging oxygenation of human tumours. Eur Radiol 17, 861-72 (2007).

12. Maurer, R.I., Blower, P.L., Dilworth, J.R., Reynolds, C.A., Zheng, Y. \& Mullen, G.E.D. Studies on the mechanism of hypoxic selectivity in copper bis(thiosemicarbazone) radiopharmaceuticals. J Med Chem 45, 1420-31 (2002).

13. Mankoff, D.A., Eary, J.F., Link, J.M., Rajendran, J.G., Spence, A.M. \& Krohn, K.A. Tumor-specific positron emission tomography imaging in patients: $\left[{ }^{18} \mathrm{~F}\right]$ 
fluorodeoxyglucose and beyond. Clin Cancer Res 13, 3460-9 (2007).

14. Rumsey, W.L., Vanderkooi, J.M. \& Wilson, D.F. Imaging of phosphorescence: a novel method for measuring oxygen distribution in perfused tissue. Science 241, 1649-51 (1988).

15. Ziemer, L.S., Lee, W.M., Vinogradov, S.A., Sehgal, C. \& Wilson, D.F. Oxygen distribution in murine tumors: characterization using oxygen-dependent quenching of phosphorescence. J Appl Physiol 98, 1503-10 (2005).

16. Babilas, P., Liebsch, G., Schacht, V., Klimant, I., Wolfbeis, O.S., Szeimies, R-M. \& Abels, C. In vivo phosphorescence imaging of $p \mathrm{O} 2$ using planar oxygen sensors. Microcirculation 12, 477-87 (2005).

17. Dunphy, I., Vinogradov, S.A. \& Wilson, D.F. Oxyphor R2 and G2: phosphors for measuring oxygen by oxygen-dependent quenching of phosphorescence. Anal Biochem 310, 191-8 (2002).

18. Briñas, R.P., Troxler, T., Hochstrasser, R.M. \& Vinogradov, S.A. Phosphorescent oxygen sensor with dendritic protection and two-photon absorbing antenna. J Am Chem Soc 127, 11851-62 (2005).

19. Vinogradov, S.A., Lo, L-W., Jenkins, W.T., Evans, S.M., Koch, C., \& Wilson, D.F. Noninvasive imaging of the distribution in oxygen in tissue in vivo using near-infrared phosphors. Biophys J 70, 1609-17 (1996).

20. Lakowicz, J. R. Quenching of Fluorescence, in Principles of Fluorescence Spectroscopy 3rd edn. 277- 330 (Springer, New York, 2006).

21. Lemaire-Ewing, S., Prunet, C., Montange, T., Vejux, A., Berthier, A., Bessede, G., Corcos, L., Gambert, P., Neel, D. \& Lizard. Comparison of the xytotoxic, pro-oxidant and pro-inflamatory characteristics of different oxysterols. Cell Biol Toxicol 21, 97-114 (2005).

22. Varghese, A.J., Gulyas, S. \& Mohindra, J.K. Hypoxia-dependent reduction of 1-(2-nitro-1-imidazolyl)-3-methoxy-2-propanol by Chinese hamster ovary cells and KHT tumor cells in vitro and in vivo. Cancer Res 36, 3761-5 (1976).

23. Rajendran, J.G., Schwartz, D.L., O’Sullivan, J., Peterson, L.M., Ng, P., Scharnhorst, J., Grierson, J.R. \& Krohn, K.A. Tumor hypoxia imaging with [F-18] fluoromisonidazole positron emission tomography in head and neck cancer. Clin Cancer Res 12, 5435-41 (2006).

24. Barthel, H., Wilson, H., Collingridge, D.R., Brown, G., Osman, S., Luthra, S.K., Brady, F., Workman, P., Price, P.M. \& Aboagye, E.O. In vivo evaluation of 
$\left[{ }^{18} \mathrm{~F}\right]$ fluoroetanidazole as a new marker for imaging tumour hypoxia with positron emission tomography. Br J Cancer 90, 2232-42 (2004).

25. Lewis, J.S., Herreno, P., Sharp, T.L., Engelbach, J.A., Fujibayashi, Y., Laforest, R., Kovac, A., Glopler, R.J. \& Welch, M.J. Delineation of hypoxia in canine myocardium using PET and copper(II)-diacetyl-bis(N(4)-methylthiosemicarbazone). J Nucl Med 43, 1557-69 (2002).

26. Jain, R.K. \& Stroh, M. Zooming in and out with quantum dots. Nat Biotechnol 22, 959-60 (2004).

27. de Chermont, Q.l.M., Chaneac, C., Seguin, J., Pelle, F., Maitrejean, S., Jolivet, J-P., Gourier, D., Bessodes, M., \& Scherman, D. Nanoprobes with near-infrared persistent luminescence for in vivo imaging. Proc Natl Acad Sci U S A 104, 9266-71 (2007).

28. Weissleder, R., Kelly, K., Sun, E.Y., Shtatland, T. \& Josephson, L. Cell-specific targeting of nanoparticles by multivalent attachment of small molecules. Nat Biotechnol 23, 1418-23 (2005).

29. Gao, X., Cui, Y., Levenson, R.M., Chung, L.W. \& Nie, S. In vivo cancer targeting and imaging with semiconductor quantum dots. Nat Biotechnol 22, 969-76 (2004).

30. Michalet, X., Pinaud, F.F., Bentolia, L.A., Tsay, J.M., Doose, S., Li, J.J., Sundaresan, G., Wu, A.M., Gambhir, S.S., \& Weiss, S. Quantum dots for live cells, in vivo imaging, and diagnostics. Science 307, 538-44 (2005).

31. Kaijzel, E.L., van der Pluijm, \& Löwik, G.C.W. Whole-body optical imaging in animal models to assess cancer development and progression. Clin Cancer Res 13, 3490-7 (2007).

32. Blodgett, T.M., Meltzer, C.C. \& Townsend, D.W. PET/CT: form and function. Radiology 242, 360-85 (2007).

33. Suematsu, M., Goda, N., Sano, T., Kashiwagi, S., Egawa, T., Shinoda, Y., \& Ishimura, Y. Carbon monoxide: an endogenous modulator of sinusoidal tone in the perfused rat liver. J Clin Invest 96, 2431-7 (1995). 


\section{FIGURE LEGENDS}

Figure 1. Spectral properties of BTP

(a) Chemical structure of $\operatorname{Ir}(\mathrm{btp})_{2}$ (acac) (BTP)

(b) Absorption (green line) and phosphorescence (red line) spectra of BTP in 1,2-dichloroethane at room temperature.

Figure 2. Cell imaging with BTP

(a) BTP imaging of the three cell lines CHO, HeLa, and U251. The cells were placed at 20\% $\mathrm{O}_{2}$ (upper panel) and 5\% $\mathrm{O}_{2}$ (lower panel).

(b) HeLa cells were placed at $20 \%, 10 \%, 5 \%$, or $2.5 \% \mathrm{O}_{2}$ concentration. Upper panel, BTP loading. Lower panel, HIF1 $\alpha$ immunostaining.

(c) Western blot of HIF1 $\alpha$. HeLa cell lysates were subjected to SDS-PAGE after incubation with $20 \%, 10 \%, 5 \%$, or $2.5 \% \mathrm{O}_{2}$.

Figure 3. In vivo imaging with BTP.

(a) Tumor imaging. Tumor-bearing athymic nude mice were injected with $250 \mathrm{nmol} \mathrm{BTP} / 100$ $\mu \mathrm{l}$ DMSO from the tail vein. For BTP imaging, a tumor-bearing mouse was anesthetized by injecting pentobarbital (1.0 mg/mouse) intraperitoneally. The tumor image was obtained at 0 , 5 and 60 min after the BTP injection.

(b) Removal of BTP from the SCC-7 tumor. After BTP injection (250 nmol/mouse), BTP image was chased for $48 \mathrm{~h}$. The intensity of BTP image was evaluated by assuming 0 min point image intensity as 1.0.

Figure 4. Tumor detection limit of BTP image.

SCC-7 cells were injected into three nude mice, and tumor size was measured periodically. The diameter of the tumor was obtained by subtracting the thickness of skin. For imaging the tumor, $250 \mathrm{nmol} \mathrm{BTP/100} \mu \mathrm{l}$ was injected into a tumor-bearing mouse, and tumor image was obtained $1 \mathrm{~h}$ after the injection. The intensity of BTP image was evaluated by assuming 0 min point image intensity as 1.0. Visual limit was plotted by a red broken line, and arrows indicate 
Zhang et al./First submission

a visible region. The tumor diameter and intensity of BTP image of the three tumor-bearing mice are shown by the three symbols, circle, triangle, and square for each mouse. 
Table $1 \mathrm{pO}_{2}$ levels in tumors

\begin{tabular}{cc}
\hline & $\mathrm{pO}_{2}(\mathrm{mmHg})$ \\
\hline SCC-7 & $18.3 \pm 0.8$ \\
U87MG & $19.4 \pm 1.7$ \\
RAMOS & $20.3 \pm 0.6$ \\
HT-29 & $18.9 \pm 0.8$ \\
LL-2 & $19.7 \pm 0.6$ \\
\hline
\end{tabular}

Tumor $\mathrm{pO}_{2}$ was measured by a needle-type polarographic oxygen electrode. The $\mathrm{PO}_{2}$ in each tumor stayed in a narrow range before and after BTP imaging. Values are the mean \pm $\mathrm{SD}$ of at least five independent experiments. 
Figure 1

a

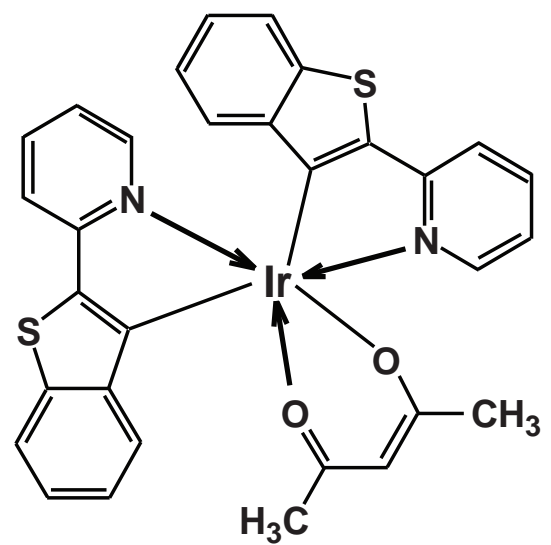

b

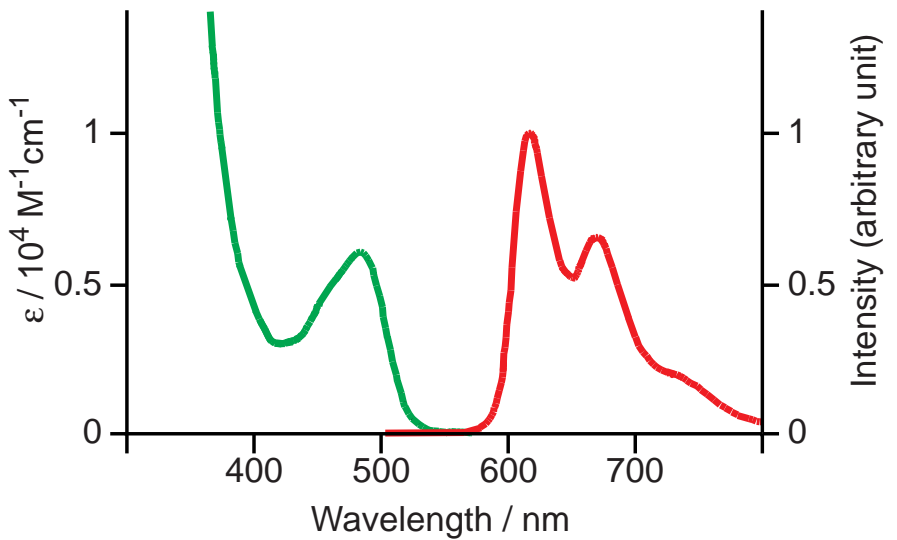


Figure 2

a

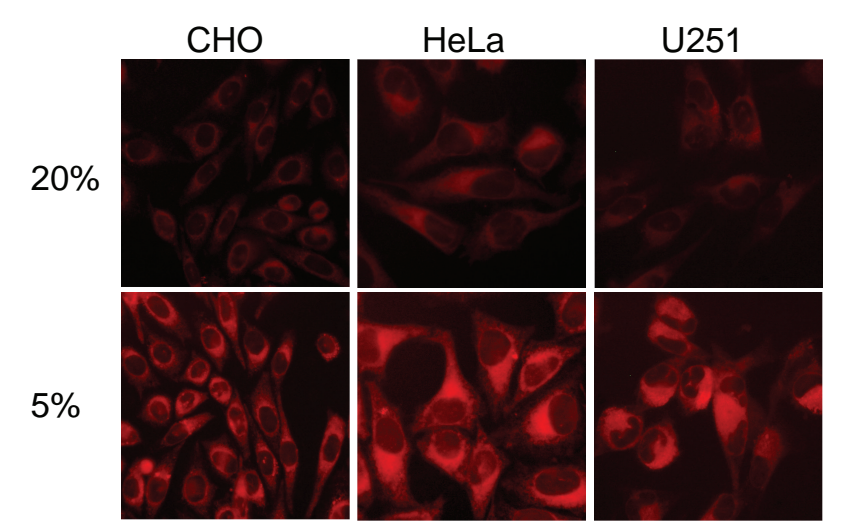

b
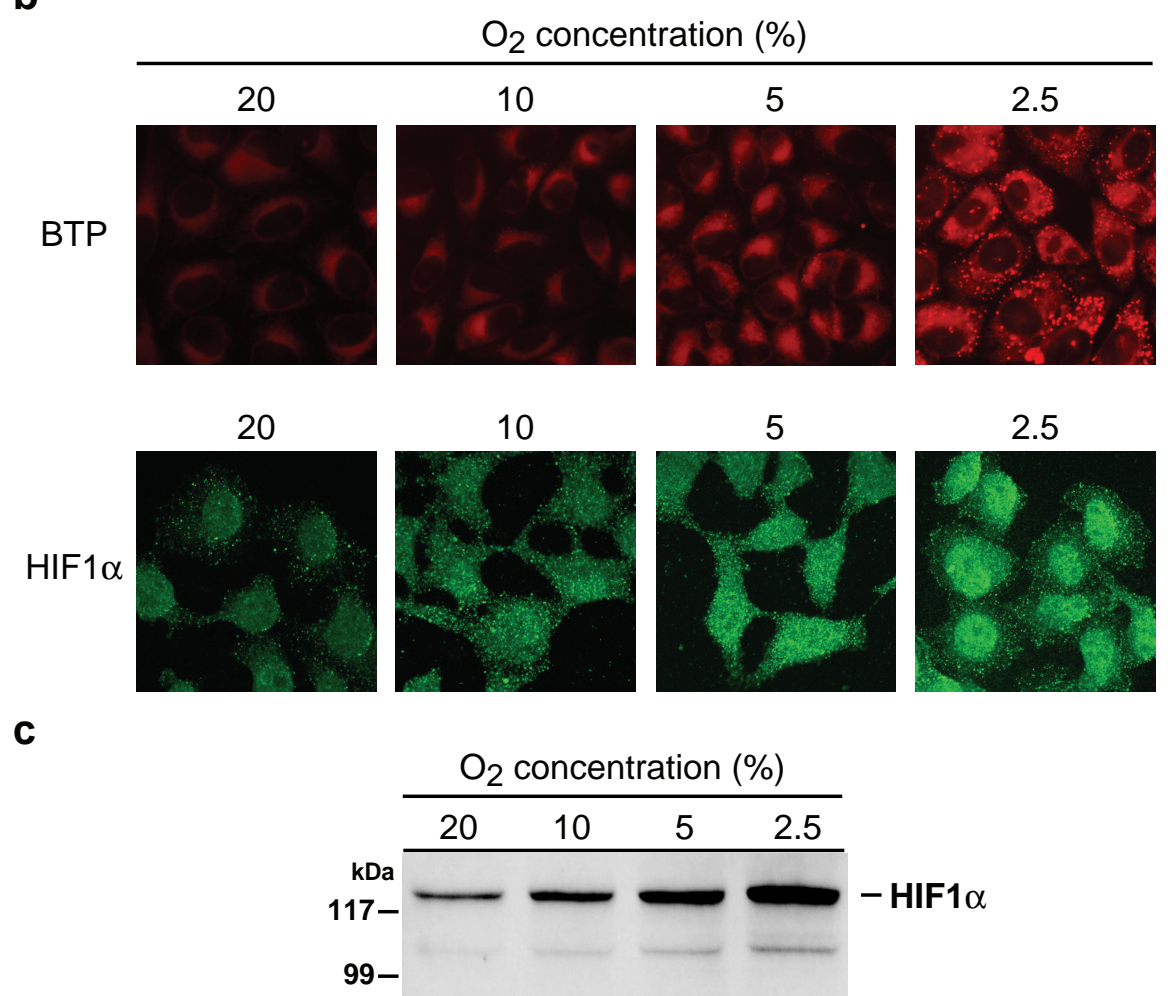
Figure 3

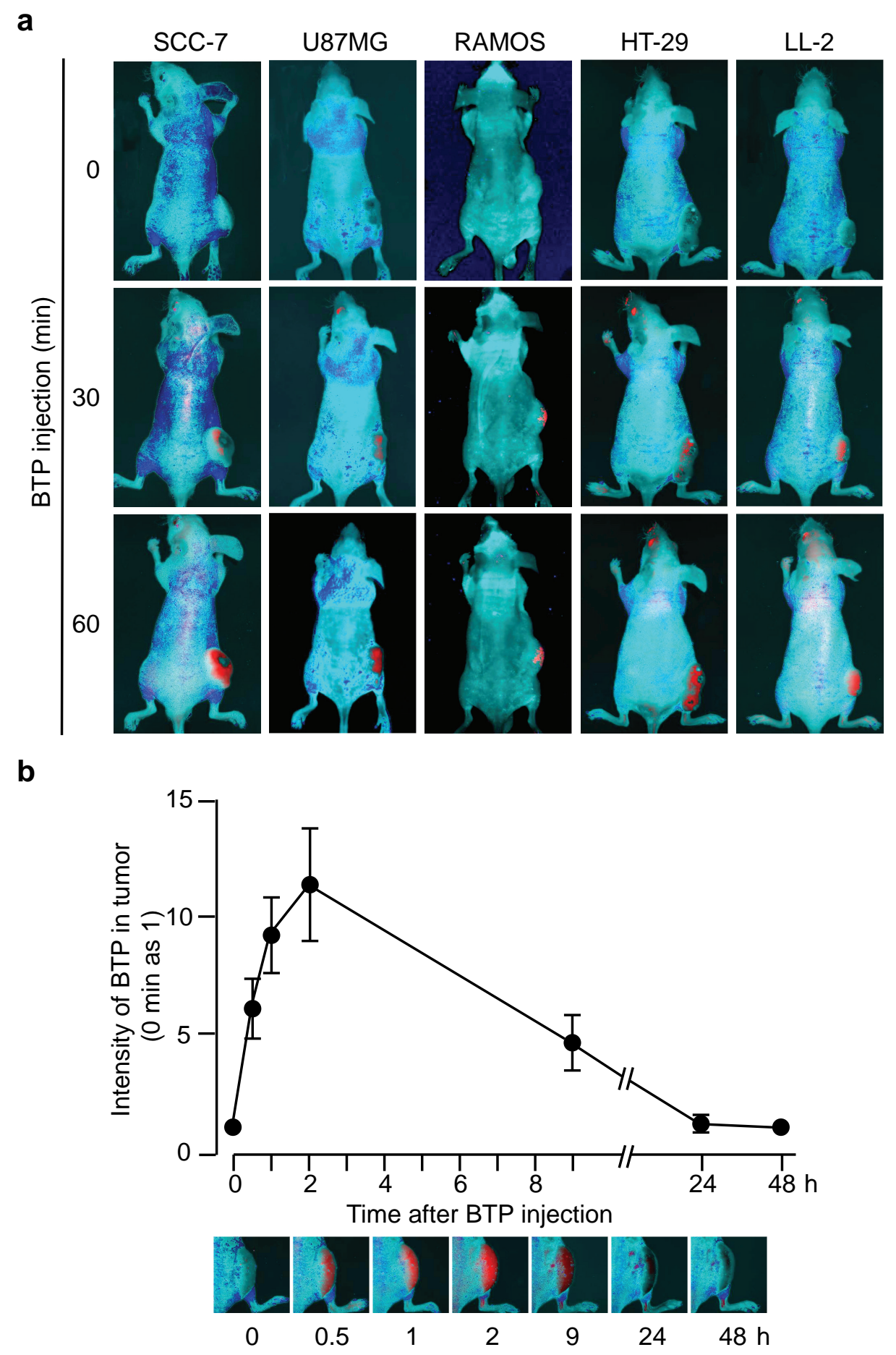


Figure 4

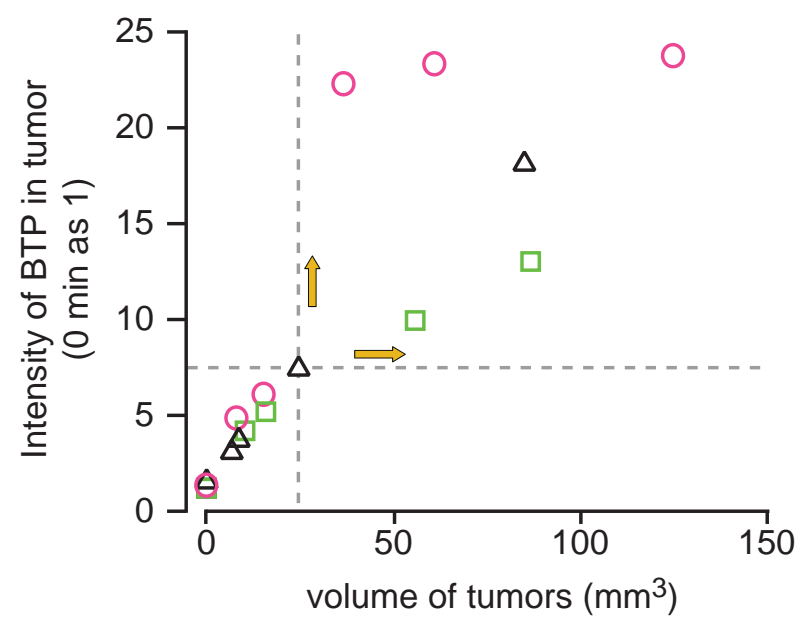

